\title{
1 The impact of heat on human physical work 2 capacity; part III: the impact of solar 3 radiation varies with air temperature, 4 humidity, and clothing coverage.
}

5 Josh Foster, ${ }^{1}$ James W Smallcombe, ${ }^{1}$ Simon Hodder, ${ }^{1}$ Ollie Jay, ${ }^{2}$ Andreas D Flouris, ${ }^{3}$ Lars

6 Nybo, ${ }^{4}$ George Havenith ${ }^{1}$

$8{ }^{1}$ Environmental Ergonomics Research Centre, Loughborough University, LE11 3TU, UK.

$9 \quad{ }^{2}$ Thermal Ergonomics Laboratory, University of Sydney, Sydney, NSW, Australia.

$10 \quad{ }^{3}$ FAME Laboratory, University of Thessaly, Trikala, Greece

$11{ }^{4}$ Department of Nutrition, Exercise and Sports, University of Copenhagen, Copenhagen,

12 Denmark

13 Word count: 5,407

14 Word count adding 250 for each Table/Figure: 6,657

$15 *$ Correspondence:

16 Professor George Havenith

17 Environmental Ergonomics Research Centre

18 Loughborough University

19 Loughborough, LE11 3TU

20 Leicestershire, UK

21 E: G.Havenith@lboro.ac.uk

23 Keywords: heat stress, performance, WBGT, UTCI, sunlight, labor capacity 


\section{Abstract}

25 It is well-known that heat impacts human labour/physical work capacity (PWC), but systematic

26 evaluations of solar radiation (SOLAR) effects and the interaction with air temperature and

27 humidity levels and clothing are lacking, as most lab-studies are conducted in semi-nude subjects

28 without radiation or only in a single climatic condition. Due to the high relevance of SOLAR in

29 various occupations, this study quantified how SOLAR interacts with clothing and other primary

30 environmental factors (air temperature/humidity) of importance to determine PWC in the heat.

31 The data allowed the development of a SOLAR correction factor for predicting PWC in major

32 outdoor industries. Fourteen young adult males ( 7 wearing a standardised work coverall $(0.9$

$33 \mathrm{Clo}), 7$ with shorts and trainers $(0.3 \mathrm{Clo})$ walked for 1 -hour at a fixed heart rate of $130 \mathrm{~b} \cdot \mathrm{min}^{-1}$, in

34 seven combinations of air temperature $\left(25\right.$ to $\left.45^{\circ} \mathrm{C}\right)$ and relative humidity (20 or $\left.80 \%\right)$, with and

35 without SOLAR ( $800 \mathrm{~W} / \mathrm{m}^{2}$ from solar lamps). Cumulative energy expenditure in the heat,

36 relative to the work achieved in a cool reference condition, was used to determine PWC\%. Skin

37 temperature was the primary determinant of PWC in the heat. In dry climates with exposed skin

38 (0.3 Clo), SOLAR caused PWC to decrease exponentially with rising air temperature, whereas

39 work coveralls $(0.9$ Clo) negated this effect. In humid conditions, the SOLAR-induced reduction

40 in PWC was consistent and linear across all levels of air temperature, and clothing conditions.

41 WBGT and UTCI based prediction equations of PWC represented SOLAR correctly. For heat

42 indices not intrinsically accounting for SOLAR, correction factors are provided enabling

43 forecasting of heat effects on work productivity. 


\section{Introduction}

46 Environmental heat exposure has a negative impact on human health and physical working

47 capacity (PWC) (Flouris et al., 2018; Foster et al., 2021b, 2021a; Ioannou et al., 2021), incurring

48 significant economic damage through its impact on workplace productivity (Hsiang et al., 2017;

49 Hübler et al., 2008; Zander et al., 2015). Understanding the full effect of heat on PWC is

50 required for economic cost and general impact analysis associated with climate change and hot

51 weather events in general (Hsiang et al., 2017). While models of PWC based on various climate

52 indices have recently been developed (Dunne et al., 2013; Foster et al., 2021b; Kjellstrom et al.,

53 2018), at present, none account for the effect of solar or general thermal radiation. Given that

54 many occupational tasks involve outdoor exposure, not accounting for thermal radiation is

55 presently a significant limitation.

56 In 338 trials with work paced based on heart rate (limit of $130 \mathrm{~b} \cdot \mathrm{min}^{-1}$, [moderate to heavy

57 work]) our group recently developed empirical models for PWC based on a suite of heat stress

58 indices (Foster et al., 2021b). However, those trials were conducted without added solar radiation

59 (SOLAR). Hence, to use the equations for both conditions with and without SOLAR, correction

60 factors may be needed, especially for heat stress indices that do not intrinsically account for this

61 parameter. For example, although wet bulb temperature $\left(T_{\mathrm{wb}}\right)$, Humidex, and Heat Index strongly

62 predict PWC in shaded environments (Foster et al., 2021b), they are calculated from $T_{\mathrm{a}}$ and $\mathrm{Rh}$

63 alone, and therefore cannot accommodate conditions in which there is additional SOLAR.

64 Moreover, while wet-bulb globe temperature (WBGT) and universal thermal climate index

65 (UTCI) account for radiation in their calculation (Havenith and Fiala, 2015), their correct

66 sensitivity to radiation must also be validated empirically. For WBGT and UTCI, one equation 
67 linking PWC to the thermal climate would be expected since they account for radiation, whereas

68 correction factors may be required for $T_{\mathrm{wb}}$, Humidex, and Heat Index.

69 Thermal radiation is electromagnetic radiation emitted from hot surfaces, with the precise

70 waveband characteristics dependent on the surface temperature of the emitting material (Miller,

71 2012). When electromagnetic radiation is absorbed and retained by the human body, it increases

72 body heat content which elevates thermal and cardiovascular strain (Bröde et al., 2008, 2010a).

73 Studies involving outdoor activity in the sun show marked elevations in thermal strain compared

74 with shaded conditions, for the same air temperature $\left(T_{\mathrm{a}}\right)$ (Adolph, 1947; Gonzalez et al., 2012;

75 Hardy and Stoll, 1954; Nielsen et al., 1988; Otani et al., 2017, 2019). The detrimental effects of

76 radiation on thermal strain (Gagge and Hardy, 1967; Nielsen, 1990; Stolwijk and Hardy, 1965),

77 maximal exercise performance (Otani et al., 2016), cognitive function (Piil et al., 2020), and

78 thermal comfort (Hodder and Parsons, 2007) have also been investigated with SOLAR lamps, a

79 source of artificial, non-ionising radiation.

80 Given the interaction between SOLAR and the level of human heat strain, exposure to sunlight

81 during physical work is likely to reduce PWC. However, the extent to which SOLAR influences

82 PWC across wide variations of $T_{\mathrm{a}}$ and relative humidity (Rh) is unknown. For example, the

83 impact of SOLAR on PWC may depend on the pre-existing climate, or, presuming a fixed solar

84 load, may be consistent regardless of the environment. Moreover, it is unknown to what extent

85 protective clothing alters this response. While clothing colour and fabric can have a significant

86 impact on overall solar heat gain (Bröde et al., 2008, 2010b; Nielsen, 1990), direct comparisons

87 between exposed and clothed skin are unavailable. The above knowledge is essential for accurate

88 PWC forecasting, and to determine what combinations of $T_{\mathrm{a}}$ and $\mathrm{Rh}$ should be targeted with

89 shading solutions and clothing modifications. 
90 The primary aim of this study was to quantify the impact of SOLAR on PWC, based on clothing

91 coverage (low or high), across a wide range of temperature and relative humidity combinations

$92\left(T_{\mathrm{a}}: 25-45 \mathrm{C}\right.$ Rh: $\left.20-80 \%\right)$. The secondary aim was to generate correction factors so PWC can be

93 modelled outdoors using heat stress indices that do not ordinarily account for SOLAR in their

94 calculation (namely $T_{\mathrm{wb}}$, Humidex, and Heat Index). The final aim was to test the sensitivity of

95 WBGT and UTCI to added solar heat loads, confirming whether our earlier published functions

96 (Foster et al., 2021b) can be used for indoor and outdoor work settings. 


\section{Methodology}

\section{Overview}

99 Participants were randomly allocated into either a low or high clothing coverage group (between

100 participant), and subsequent within participant comparisons (i.e., SOLAR vs SHADE) took

101 place in different $T_{\mathrm{a}}$ and Rh combinations. We adopted a physical work protocol in a climate

102 chamber which simulates the self-pacing behaviours adopted in the field. We refer the reader to

103 our companion paper (Foster et al., 2021b) for a thorough rationale and description of the

104 protocol. A study schematic is shown in Figure 1.

\section{Ethical approval}

106 This study was approved by the Loughborough University Ethics Committee and was performed

107 in-line with the Declaration of Helsinki. Participants were provided with an information sheet

108 that detailed the risks and requirements of the experiment before providing written informed

109 consent. Participants conducted a health screening questionnaire prior to the start of the

110 experiments.

\section{Location and timeline}

112 The data collection took place in custom made environmental chambers (TISS performance

113 chambers, UK) located within the Environmental Ergonomics Research Centre, Loughborough

114 University. Data collection ran from September 2018 to May 2019.

\section{Participants}

116 A total of thirteen participants took part in the study. The total number of trials performed varied

117 between participants, ranging from 4-14 (median = 10). Table 1 displays participant 
118 characteristics for each experimental group. To reduce any impact of heat acclimation

119 throughout the trial period, the number of experiments were capped at three per week, but

120 seldom exceeded two per week. The fixed heart rate approach also limits any sustained rises in

121 body temperature that are required on a daily basis to elicit a heat acclimated phenotype (Foster

122 et al., 2021b; Fox et al., 1963). Moreover, participants were not permitted to take part in the

123 study if they recently visited a hot climate. 


\section{Experimental Design}

127 Thirteen young adult male participants were allocated to either a low or high clothing coverage

128 group. One participant completed trials in both clothing conditions, totalling $\mathrm{n}=7$ in each.

129 Participants first completed a graded exercise test on a treadmill to determine maximal oxygen

130 consumption $\left(V \square \mathrm{O}_{2 \max }\right)$. Participants then completed 1 hour of walking exercise at a fixed heart

131 rate of $130 \mathrm{~b} \cdot \mathrm{min}^{-1}$, first in a reference cool condition, and thereafter in up to seven different

132 combinations of $T_{\mathrm{a}}$ and $\mathrm{Rh}$. In terms of the $T_{\mathrm{a}}$ and $\mathrm{Rh}$ combination, trials were completed in a

133 randomised order, but a solar vs. no solar comparison trial was always completed sequentially

134 (i.e., one followed the other, though always on separate days). A total of 66 and 62 hot trials

135 were completed in low and high clothing coverage, respectively. In the supplementary file, Table

136 S1 displays the number of trials performed by each participant according to the air temperature

137 and relative humidity combination. A study schematic is shown in the supplementary file (Figure

138 S1). 


\section{Experimental controls}

141 Participants completed experimental sessions at the same time of day to minimise the effect of

142 circadian rhythm on outcome variables (Waterhouse et al., 2004). However, it is worth noting

143 that, apart from changes in absolute core temperature, physiological effector responses are

144 unaffected by time of day (Ravanelli and Jay, 2020). Participants presented to the lab in a

145 hydrated state (confirmed by urinary analysis), and refrained from caffeine 12 hours prior to each

146 trial. Finally, participants were asked to refrain alcohol and vigorous exercise 24 hours before

147 each trial.

\section{Preliminary trial (visit 1)}

149 The preliminary visit involved an anthropometric assessment and a submaximal (walking) test of

150 maximal oxygen consumption $\left(V \square \mathrm{O}_{2 \max }\right)$ performed on a treadmill. Body composition was

151 assessed using a Tanita scale (MC-780MA, TANITA Corporation, Japan) while participants

152 were dressed in underwear only. At a fixed walking speed of $4.5 \mathrm{~km} / \mathrm{hour}$, the submaximal test

153 followed a ramp protocol in which the gradient increased by 5\% every 3 minutes until a steady

154 state heart rate of $85 \%$ age predicted maximum was attained. Combined with indirect calorimetry

155 to continuously assess $V \square \mathrm{O}_{2}$ uptake, $V \square \mathrm{O}_{2 \max }$ was predicted by extrapolating $V \square \mathrm{O}_{2}$ to age

156 predicted maximum heart rate. The protocol is set out in more detail in our companion paper

157 (Foster et al., 2021b).

\section{Experimental protocol}

159 Upon arrival, participants inserted a rectal thermistor (VIAMED, Yorkshire, UK) to a depth of

$16010 \mathrm{~cm}$ past the anal sphincter to monitor internal (rectal) temperature, which allowed continuous

161 monitoring of core temperature throughout each trial. Participants subsequently voided their 
162 bladder and provided a urine sample which was used for the assessment of urine specific gravity.

163 If urine specific gravity exceeded 1.020, participants drank $500 \mathrm{ml}$ of water and provided another

164 sample after 20 minutes (Armstrong et al., 1994). Skin thermistors (Grant Instruments Ltd,

165 Corby, UK) were then placed onto each participant at 6 sites, allowing continuous measurement

166 of skin temperature $\left(T_{\text {skin }}\right)$. Thermistors were attached to the following sites with a breathable,

167 hypafix tape (BSN medical, D-22771, Hamburg, Germany); the upper back, lower back, chest,

168 arm (triceps), thigh (quadriceps), and calf. The mean $T_{\text {skin }}$ was then calculated by adapting the

169 Ramanathan equation (1964). The original equation is equal to:

Original $\boldsymbol{T}_{\text {skin }}=0.3 T_{\text {chest }}+0.3 T_{\text {arm }}+0.2 T_{\text {thigh }}+0.2 T_{\text {thigh }}\left[{ }^{\circ} \mathbf{C}\right]$

171 To integrate additional skin temperature sites in the radiated area at the upper and lower back,

$172 T_{\text {chest }}$ was replaced by $T_{\text {torso }}$, providing equal weight to the front and back temperatures of the

173 torso, as below:

Adapted $\boldsymbol{T}_{\text {skin }}=0.3 T_{\text {torso }}+0.3 T_{\text {arm }}+0.2 T_{\text {thigh }}+0.2 T_{\text {thigh }}\left[{ }^{\circ} \mathbf{C}\right]$

175 Where $T_{\text {torso }}$ was calculated by:

$\boldsymbol{T}_{\text {torso }}=0.15 T_{\text {chest }}+0.075 T_{\text {upperback }}+0.075 T_{\text {lowerback }}\left[{ }^{\circ} \mathrm{C}\right]$

177 The value for mean $T_{\text {skin }}$ was reported as the average score of "adapted $T_{\text {skin" }}$ during a 1-hour 178 trial.

\section{Physical work simulation}


180 The treadmill was programmed to control workload to achieve the desired heart rate of 130

$181 \mathrm{~b} \cdot \mathrm{min}^{-1}$. The treadmill speed and grade were never manually controlled by the researchers or

182 participants. The treadmill incline did not change until the speed reached its maximum of $6 \mathrm{~km} \cdot \mathrm{h}^{-}$

183 . Thereafter, the speed did not change unless the incline fell back to zero. Each test was set to

184 last a maximum 1 hour, but in more extreme heat the speed often fell to zero before this time. If

185 speed fell to zero, (i.e., resting heart rate is $\geq 130 \mathrm{~b} \cdot \mathrm{min}^{-1}$ ) the participants exited the chamber 186 and no more exercise took place.

\section{Calculation of percentage physical work capacity}

188 A predictive equation based on treadmill speed and grade (Ludlow and Weyand, 2017) was used

189 to calculate total cumulative energy generated in the present study. The original equation was

190 expanded to convert energy generated in $V \square \mathrm{O}_{2}$ to total kilojoules. This equation, and its

191 validation based on 365 expired air samples are available in our companion paper (Foster et al.,

192 2021b).

\section{$193 \quad$ Clothing}

194 Participants were separated into two clothing groups before undertaking trials with and without

195 SOLAR radiation. The two conditions were chosen to provide minimal/low or high clothing

196 coverage of the skin. In the low clothing trials, subjects wore underwear, standardized shorts,

197 socks, and trainers. In the high clothing trials, subjects wore the same as the low clothing trial,

198 with the addition of a standardized cotton t-shirt, and a standardized full body protective coverall

199 (65\% polyester, 35\% cotton). The intrinsic clothing insulation of the low and high coverage

200 ensembles were estimated as 0.04 and $0.133 \mathrm{~m}^{-2} \cdot \mathrm{K} \cdot \mathrm{W}^{-1}(0.26$ and $0.86 \mathrm{Clo})$, respectively, based

201 on the International Standard (ISO9920, 2009). Using the equation provided in the standard, the 
202 evaporative resistance was estimated at 0.007 and $0.024 \mathrm{~m}^{-2} \cdot \mathrm{kPa} \cdot \mathrm{W}^{-1}$ for the low and high

203 clothing conditions, respectively.

\section{Environmental logging}

205 A Quest-temp model 34 meter was used to record wet-bulb globe temperature (WBGT) at 1-

206 minute intervals. The approach taken to measure WBGT is described below. A Testo model 435-

2072 with hot-wire probe was used to record $T_{\mathrm{a}}$ (shaded), $\mathrm{Rh}$, and air velocity and logged at 1-

208 minute intervals.

\section{Calculation of Heat Stress Indices}

\section{Wet bulb globe temperature (WBGT)}

211 For all shaded trials, the average value for dry bulb, wet bulb, and globe temperature were used

212 to assess WBGT (WBGT= $0.7 T_{\mathrm{wb}}+0.2 T_{\text {globe }}+0.1 T_{\mathrm{a}}$ ) for a given work bout. For the SOLAR

213 trials, live WBGT measurement was not practical since the WBGT meter needed to be placed in

214 the same location as the exercising human participant, and at different heights (radiation intensity

215 varied with height). Hence, the value for natural wet-bulb and globe were measured at four

216 heights on a separate occasion while exposed to SOLAR. The dry bulb was measured in each

217 SOLAR trial, shielded from radiation. Therefore, the same value for natural wet bulb and globe

218 temperature was used for each participant for each $T_{\mathrm{a}}$ and Rh combination with SOLAR.

\section{Psychrometric wet bulb temperature $\left(\boldsymbol{T}_{\mathrm{wb}}\right)$}

220 Psychrometric wet bulb temperature was calculated based on Bernard \& Pourmoghani (1999):

$T_{w b}=0.376+5.79 P_{\mathrm{a}}+\left(0.388-0.0465 \mathrm{P}_{a}\right) T_{\mathrm{db}}\left[{ }^{\circ} \mathrm{C}\right]$ 
222 Where $P_{\mathrm{a}}$ is the ambient water vapour pressure measured in $\mathrm{kPa}$, and $T_{\mathrm{db}}$ is the dry bulb

223 temperature (air temperature). $\mathrm{P}_{\mathrm{a}}$ was calculated using the following equation (Parsons, 2010):

$P_{a}=e^{\left(18.956-4030.18 T_{a}+235\right)} \times \frac{R h}{100}[\mathrm{kPa}]$

225 Where $T_{\mathrm{a}}$ is ambient temperature in ${ }^{\circ} \mathrm{C}$, and $\mathrm{Rh}$ is relative humidity (0-100).

\section{Universal Thermal Climate Index (UTCI)}

227 UTCI was calculated for each condition in excel (www.climatechip.org/excel-wbgt-calculator),

228 which uses a 6 parameter polynomial model (Bröde et al., 2012). $T_{\mathrm{a}}, \mathrm{Rh}$, globe temperature and 229 air velocity were used for the calculation.

\section{Humidex}

231 The Humidex was computed as below (Masterton and Richardson, 1979; Rana et al., 2013):

Humidex $=T_{\mathrm{a}}+\frac{5}{9}\left(\left[6.112 \times 10^{\left(\frac{7.5 T_{\mathrm{a}}}{237.7+T_{\mathrm{a}}}\right)} \times \frac{R h}{100}\right]-10\right)$

233 Where $T_{\mathrm{a}}$ is air temperature in degrees Celsius; $R h$ is relative humidity in $\%(0-100)$.

\section{$234 \quad$ Heat Index}

235 The Heat Index was computed as below (Rothfusz, 1990):

$$
\begin{aligned}
& \text { Heat Index }=- \\
& \qquad \begin{aligned}
& 2.379+2.04901523 T_{\mathrm{a}}+10.14333127 R h-0.22475541 T_{\mathrm{a}} \cdot R h-6.83783 \\
& \times 10^{-3} T_{\mathrm{a}}^{2}-5.481717 \times 10^{-2} R h^{2}+1.22874 \times 10^{-3} T_{\mathrm{a}}^{2} \cdot R h+8.5282 \times 10^{-4} T_{\mathrm{a}} \\
& \cdot R h^{2}-1.99 \times 10^{-6} T_{\mathrm{a}}^{2} \cdot R h^{2}\left[{ }^{\circ} \mathrm{F}\right]
\end{aligned}
\end{aligned}
$$


237 Where $T_{\mathrm{a}}$ is in degrees Fahrenheit and $\mathrm{Rh}$ is $0-100$. The Heat Index in Fahrenheit $\left(\mathrm{HI}_{\mathrm{F}}\right)$ was

238 converted to degrees Celsius by:

Heat Index $=\left(H I_{\mathrm{F}}-32\right) \times \frac{5}{9}\left[{ }^{\circ} \mathrm{C}\right]$

240 Solar simulation lamps

241 SOLAR was produced artificially using compact source iodide lamps (CSI, Thorn Lighting,

242 Durham, UK; (Beeson, 1978). The lamps filter out ionising radiation to negligible values, and

243 thereafter produce a similar spectral content to that of sunlight. An array of three vertically

244 aligned 1,000 $\mathrm{W}$ metal halide lamps were placed $2.3 \mathrm{~m}$ posterior to the participant. In the

245 SOLAR trials, the lamps were switched on at least 1-hour before activity. The average intensity

246 of radiation across all exposed regions for all trials was $807 \pm 24 \mathrm{~W} / \mathrm{m}^{-2}$, as measured

247 immediately before and after each experiment (Pyranometer, Kipp and sons, The Netherlands).

248 This level of SOLAR is typical for what is observed under a clear sky during the hottest part of

249 the day (Ioannou et al., 2017; Monteith and Unsworth, 1990). The projected area ( $\left.\mathrm{A}_{\mathrm{p}}\right)$ was

250 estimated at $24.2 \%$ total body surface area, based on a SOLAR altitude and azimuth of $0^{\circ}$

251 (Underwood and Ward, 1966). The average body surface area was $1.90 \mathrm{~m}^{-2}$ (range 1.69 to 2.21

$252 \mathrm{~m}^{-2}$ ), resulting in a total radiant heat load of 382 Watts (range 339 to 441 Watts).

\section{Statistical Analysis}

254 Statistical analyses were conducted using IBM SPSS version 27 and GraphPad Prism version 8.

255 In SPSS, a linear mixed model with fixed [condition (SOLAR or SHADE), temperature (three or

256 four levels depending on humidity), and clothing (low or high coverage)] and random (subject

257 ID) effects was used to compare physical work capacity (PWC\%) responses between SHADE 
258 and SOLAR trials. Four levels of temperature were assessed in dry climates $(25,35,40$, and

$\left.25945^{\circ} \mathrm{C}\right)$, and three were assessed in humid climates $\left(25,30\right.$, and $\left.35^{\circ} \mathrm{C}\right)$. Data are reported as mean

260 difference \pm standard error, $95 \%$ confidence intervals of the difference, and effect size. Effect

261 size was calculated as:

$$
\text { Effect size }=\frac{\text { Mean difference }}{S D}
$$

263 where mean difference is the group average difference between PWC in SHADE vs SOLAR,

264 and SD is the standard deviation of the differences. The threshold values of $0.2,0.5$, and 0.8

265 were used to indicate a small, moderate, and large effect, respectively (Cohen, 1988).

266 In accordance with our companion paper (Foster et al., 2021b) we used a sigmoidal expression to 267 determine the impact of heat on PWC\%. The model takes the form:

$$
\text { Physical Work Capacity } \%=100 / 1+\left(\frac{P W C 50}{x}\right)^{\text {Hillslope }}
$$

269 Where $x$ represents the predictor studied (e.g. WBGT), PWC50 is the value of $x$ that elicits $50 \%$

270 PWC, and HillSlope defines the steepness of the curve. The HillSlope and PWC50 parameters

271 were calculated from the software to find the optimal fit to the data (producing the least

272 variance). The extra sum of squares $F$ test was used to determine if best fit values of selected

273 parameters (PWC50 and Hillslope) differed significantly between SHADE and SOLAR datasets

274 (Turner et al., 2015) i.e. is the error in the model reduced using specific parameters for each

275 dataset vs using global/shared parameters. The alpha value for all significance testing was set as $276 p<0.05$. 
277 If a separate model was required for inclusion of the SOLAR data (based on a significant $F$ test),

278 correction factors were generated based on the difference in PWC\% between the SHADE and

279 SOLAR models. We then modelled the difference in PWC between the SHADE and SOLAR

280 models to form correction factors based on the solar intensity. The correction factors were then

281 used to estimate PWC during sunlight exposure, for heat indices that do not intrinsically account

282 for radiation in their calculation (i.e. $T_{\mathrm{wb}}$, humidex, and heat index). The correction factor was

283 formed based on the following template:

$$
\text { Physical Work Capacity } \%=P W C_{\text {shade }}-\left(\frac{\alpha}{800} \cdot \frac{A_{p}}{24.2} \cdot \operatorname{Sin} \theta \cdot P W C_{\text {corr }}\right)
$$

285 where $P W C_{\text {shade }}$ calculates percent $\mathrm{PWC}$ in shaded conditions, $P W C_{\text {corr }}$ is the correction factor

286 observed in this experiment and $\frac{\alpha}{800} \cdot \frac{A_{p}}{24.2} \cdot \operatorname{Sin} \theta$ is a linear scaling factor which interpolates the

287 SOLAR impact based on the present radiation. Equations for $P W C_{\text {shade }}$ are available in our 288 companion paper (Foster et al., 2021b); $\alpha$ is the SOLAR intensity in $\mathrm{W} \cdot \mathrm{m}^{-2} .800 \mathrm{~W} \cdot \mathrm{m}^{-2}$ was as

289 the reference for the radiation level used in the present experiment. Using a SOLAR intensity of

290 greater than $800 \mathrm{~W} \cdot \mathrm{m}^{-2}$ is possible but extrapolates beyond our empirical dataset rather than

291 interpolating; $A_{\mathrm{p}}$ is the projected area (the surface area of skin exposed to radiation), expressed as

292 a percentage of total body surface area. $24.2 \%$ was used in the present study and represents a

293 worst-case scenario (i.e., maximum possible surface area exposed to SOLAR). Sin $\theta$ is the sinus

294 of the angle ( $\theta$ in degrees) between the SOLAR beam and the surface onto which it projects.

$295 \operatorname{Sin} \theta$ values range from 0-1. Values for $A_{\mathrm{p}}$ can be calculated based on SOLAR altitude and 296 azimuth (Underwood and Ward, 1966). 
297 The predictive power of core and mean skin temperature for estimating PWC\% was assessed

298 using the same function as described in $\mathrm{Eq} 9$, with the $x$ value representing core or skin

299 temperature. The relationship between these two thermometric variables and WBGT were

300 assessed with a basic linear model. 
302 Results

\section{Physical work capacity}

\section{Dry climate}

305 Significant main effects were found (Fig. 1 A,C) for condition (SOLAR-SHADED) and air

306 temperature $(p<0.05)$, but not for clothing $(p>0.05)$. There was a significant 3 -way interaction

307 term, indicating that the impact of SOLAR on PWC varied with air temperature and clothing ( $p$

$308<0.05)$. In low clothing coverage, there was no effect of SOLAR on PWC at $25^{\circ} \mathrm{C}(\Delta=-1 \pm 13 \%$,

$309 \mathrm{ES}=0.09)$, or $35^{\circ} \mathrm{C}(-1 \pm 9 \%, \mathrm{ES}=1.34)$. However, SOLAR decreased $\mathrm{PWC}$ at $40^{\circ} \mathrm{C}(-7 \pm 5 \%$,

$310 \mathrm{ES}=1.32)$, and $45^{\circ} \mathrm{C}(-37 \pm 7 \%, \mathrm{ES}=5.23)$. In high clothing coverage, there was no significant

311 effect of SOLAR on PWC at $25^{\circ} \mathrm{C}$ air temperature $(-2 \pm 13 \%, \mathrm{ES}=0.14)$. However, SOLAR

312 reduced $\mathrm{PWC}$ at $35(-6 \pm 10 \%, \mathrm{ES}=0.57), 40(-12 \pm 8 \%, \mathrm{ES}=1.57)$, and $45^{\circ} \mathrm{C}(-15 \pm 12 \%$, ES

$313=1.29)$.

\section{Humid climate}

315 Main effects were found for condition and air temperature $(p<0.05)$, but not for clothing $(p>$

316 0.05) (Fig 1 B, D). There were no significant interaction terms, indicating that the impact of

317 SOLAR on PWC was not dependent on the air temperature, or clothing $(\mathrm{p}>0.05)$. In low

318 clothing coverage, SOLAR decreased PWC at $25(-12 \pm 13 \%, \mathrm{ES}=0.95), 30(-20 \pm 15 \%, \mathrm{ES}=$

$3191.39)$, and $35^{\circ} \mathrm{C}$ air temperature $(-15 \pm 3 \%, \mathrm{ES}=4.96)$. In high clothing coverage, SOLAR

320 reduced $\mathrm{PWC}$ at $25(-9 \pm 9 \%, \mathrm{ES}=1.03), 30(-7 \pm 7 \%, \mathrm{ES}=1.03)$, and $35^{\circ} \mathrm{C}$ air temperature $(-9$

$321 \pm 8 \%, \mathrm{ES}=1.11)$

322 The individual level PWC responses in each condition are available in the supplementary

323 material. 


\section{Role of skin and core temperature in predicting physical work} 326 capacity.

327 Figure 2 (panels A and B) shows the independent effect of skin and core temperature (average of

328 each trial) on PWC. During physical activity at a fixed heart rate of $130 \mathrm{~b} \cdot \mathrm{min}^{-1}$ (which broadly

329 reflects the self-pacing behaviour of workers), the skin, but not core temperature, is a predictor of

330 PWC in the heat. While SOLAR results in a higher $T_{\text {skin, }}$, the predictive power of $T_{\text {skin }}$ for

331 estimating PWC does not appear to be impacted by addition of SOLAR as additional predictor in

332 the equation, indicating that the same PWC relation holds true for both SOLAR and non-SOLAR

333 conditions $\left(\mathrm{R}^{2}=0.69\right)$. Figure 2 (panels $\mathrm{C}$ and $\mathrm{D}$ ) shows the skin and core temperature response

334 to increased environment heat stress, using WBGT as an example heat index. WBGT was a

335 strong predictor of $T_{\text {skin, }}$ and the strength of the prediction was not impacted by the inclusion of

336 SOLAR data $\left(\mathrm{R}^{2}=0.82\right.$. Analysis demonstrated that for both models in Figure 2 (A and C),

337 separate parameter values are not required for the shade and SOLAR datasets $(p>0.05)$. It is

338 recommended that the equation for each model is taken from our recently published study using

339 a larger dataset (Foster et al., 2021b). The primary aim of this analysis was to determine whether

340 separate parameter values are required for the SOLAR data, which there were not.

$341 * * *$ Insert Figure 2 near here $* * *$

\section{Modelling physical work capacity with solar radiation}

343 The WBGT and UTCI thermal indices account for SOLAR in their calculation, and therefore, a

344 pooled model accounts well for both SHADE and SOLAR data. In both clothing conditions

345 (Figure 3), changing the model parameters (PWC50 and Hillslope) for the SOLAR data did not 
346 improve the fit compared to a pooled model $(p<0.05)$. In other words, the WBGT and UTCI

347 account well for the decrease in PWC with SOLAR, indicated by a rightward shift in their value

348 under SOLAR exposure. This was true in both clothing conditions. Consequently, the inclusion

349 of data with SOLAR does not negatively impact the error variance in the model, so there is no

350 requirement to adapt the models already presented in our companion paper (Foster et al., 2021b).

351 Since the $T_{\mathrm{wb}}$, Humidex, and Heat Index do not intrinsically account for thermal radiation, their

352 values for a certain $T_{\mathrm{a}} / \mathrm{Rh}$ combination are unchanged with SOLAR, and the inclusion of SOLAR

353 data decreases the predictive capacity of the model substantially. Hence, those heat stress indices

354 require separate models for the SOLAR and SHADE $(p<0.05)$, since less residual variance was

355 documented if separate models were produced for each dataset. This was true in both clothing

356 conditions. For the heat stress indices that cannot use a pooled/global model, the difference

357 between the SHADE and SOLAR functions were modelled from a gaussian expression. Those

358 functions were used to form the correction factors (Table 2), where PWC predictions obtained

359 from SHADE data are adjusted based on the solar load. These equations are based on the red

360 area fill in Figure 3, which show the difference in PWC between SOLAR and SHADE

361 conditions.

$362 * * *$ Insert Figure 3 near here $* * *$ 
365 These correction factors are for the full SOLAR load used in the experiment. Assuming a linear

366 impact of the SOLAR intensity (based on the heat transfer into the body), for lower radiation

367 levels, lower radiated areas and different SOLAR angles, the SOLAR impact can be scaled as:

radiation scale factor

$$
=\frac{\text { actual intensity } W \cdot m^{-2}}{800 W \cdot m^{-2}} \times \frac{\text { actual radiated area } \%}{24.2 \%} \times \sin (\text { Alpha })
$$

369 With Alpha=angle (in ${ }^{\circ}$ ) between radiation beam and projected surface; i.e. when radiation falls

370 perpendicular onto surface, Alpha $=90^{\circ}$.

\section{Example calculation}

372 Below we provide an example calculation assuming a $T_{\mathrm{wb}}$ of $30^{\circ} \mathrm{C}$, a SOLAR intensity of 600

$373 \mathrm{~W} \cdot \mathrm{m}^{-2}$, projected over $15 \% \mathrm{BSA}$, and the radiation hitting the radiated surface at an angle of $45^{\circ}$

374 (0.785 radians), with low clothing coverage.

$$
\boldsymbol{P W C} \%=\left[100 / 1+\left(\frac{30.98}{T_{\mathrm{wb}}}\right)^{-5.90}\right]-\left[\frac{600}{800} \times \frac{15}{24.2} \times \sin (0.785)\left(21.04 \times e^{\left[-0.5\left(\frac{30-30.51}{8.505}\right)^{2}\right]}\right)\right] \quad \mathbf{E q} \mathbf{1 6}
$$

376 In this example, PWC is $48 \%$. Without any SOLAR, PWC would be $55 \%$. Note that the

377 original/base model of PWC (the left term to the right of the equal sign) should be taken from

378 our companion paper (Foster et al., 2021b). 


\section{Discussion}

380 This study builds on our earlier publication that determined Physical Work Capacity across a

381 wide range of combinations of temperature and humidity (Foster et al., 2021b), but without

382 SOLAR present. The primary aim of the present study was to determine the additional impact of

383 SOLAR on human physical work capacity (PWC), with high and low clothing coverage and

384 across a broad range of temperature and humidity combinations. The secondary aim was to

385 evaluate whether PWC can be predicted outdoors with SOLAR using a variety of heat stress

386 indices and finally whether our previously published functions linking PWC to the climate

387 parameters can be used for both indoor (shade) and outdoor (SOLAR) work settings.

388 SOLAR reduced PWC by up to a further $20 \%$, depending on the temperature, humidity, and

389 clothing condition. We found the impact of SOLAR not to be 'additive' (Lloyd and Havenith,

390 2016), to the temperature, humidity, and clothing effects, but instead to show an interaction

391 effect with these variables. With low clothing coverage in dry heat, SOLAR had a negligible

392 impact on PWC when $T_{\mathrm{a}} \leq 35^{\circ} \mathrm{C}$, but PWC decreased exponentially due to SOLAR when $T_{\mathrm{a}} \geq$

$39340^{\circ} \mathrm{C}$ (Figure $\left.1 \mathrm{~A}\right)$. When high clothing coverage was adopted in the same climate types, SOLAR

394 caused a consistent linear decrease in PWC when $T_{\mathrm{a}} \geq 35^{\circ} \mathrm{C}$ (Figure 1C). In humid conditions,

395 the impact of SOLAR was more consistent with an additive model in that the reduction in PWC

396 caused by SOLAR was similar across all levels of $T_{\mathrm{a}}$ investigated, but slightly lower with high

397 clothing coverage (Figure 1 B and D). Based on our data (comparing figs 2a to 2b), high clothing

398 coverage only seems to protect against reductions in PWC caused by SOLAR when $T_{\mathrm{a}} \geq 40^{\circ} \mathrm{C}$,

399 with the caveat that more protection from ultraviolet radiation may be required if low clothing

400 coverage is adopted i.e., with sunscreen. The effect of sunscreen on human thermoregulatory

401 function seems to also depend on the climate type (Connolly and Wilcox, 2000) and the 
402 composition of the ointment (Aburto-Corona and Aragón-Vargas, 2016), making any potential

403 interaction difficult to predict at this stage.

404 In low clothing coverage (exposed skin), PWC was severely affected by SOLAR at $45^{\circ} \mathrm{C} / 20 \%$

$405 \mathrm{Rh}$, but the effect was substantially less with high clothing coverage for the $T_{\mathrm{a}}$ (Figure 1). Similar

406 'protective' effects of high clothing coverage during military marching in hot-dry conditions

$407\left(43.3^{\circ} \mathrm{C}\right)$ with SOLAR have been described, evidenced by a substantial decrease in sweat output

408 (Adolph, 1947). The response seems to be explained by the absolute skin temperature with

409 SOLAR, which was greater at $45^{\circ} \mathrm{C} T_{\mathrm{a}} / 20 \% \mathrm{Rh}$ in low clothing coverage $\left(37.6 \pm 0.3^{\circ} \mathrm{C}\right)$

410 compared with high clothing coverage $\left(36.6 \pm 0.1^{\circ} \mathrm{C}\right)$. It is likely that the lower skin temperature

411 in high clothing coverage is due to reflective properties of the clothing ensemble and the

412 interruption of the direct radiation to the skin by absorption, which serve to reduce direct dry

413 heat gain from SOLAR (Bröde et al., 2010a; Clark and Cena, 1978). However, it is worth noting

414 that the beneficial impact of clothing depends on the colour and fabric properties (Bröde et al.,

415 2010b; Nielsen, 1990). In dry heat when $T_{\mathrm{a}} \leq 35^{\circ} \mathrm{C}$, where no effect on PWC of adding SOLAR

416 was observed, the added radiative heat gain was likely compensated for by increased sweat

417 evaporation in low clothing coverage compared with high clothing coverage.

418 Mean skin temperature was a strong predictor of PWC in the heat, independent of clothing or

419 exposure to SOLAR (Figure 2). In contrast, the core temperature had no predictive value for

420 PWC at our chosen work rate. These findings are supported by prior work from our group

421 (Foster et al., 2021b) and others (Ioannou et al., 2017; Jay et al., 2019), which implicates $T_{\text {skin }}$ as

422 the primary determinant of work capacity loss during occupational heat stress. Mechanistically, a

423 study in mice showed that the strength of the afferent nervous system response is directly 
424 proportional to the absolute (not relative) skin temperature during heating (Ran et al., 2016),

425 providing strong theoretical basis for our observations.

426 A fixed cardiovascular strain model was chosen as a proxy for self-paced physical work based on

427 a plethora of field data in which workers can freely adjust their pace in hot climates (Bates and

428 Schneider, 2008; Kalkowsky and Kampmann, 2006; Mairiaux and Malchaire, 1985; Miller et al.,

429 2011; Wyndham, 1973). Discussing data from the South African gold mines (Wyndham, 1973),

430 Vogt et al., (1983) observed that "while productivity and oxygen consumption fell off with

431 increasing wet-bulb temperature, heart rates remained constant around an average of 130-140

$432 \mathrm{~b} \cdot \mathrm{min}^{-1}$. A heart rate of $130 \mathrm{~b} \cdot \mathrm{min}^{-1}$ was therefore chosen, which also represented an occupational

433 intensity on the border of moderate to heavy physical work, as suggested by the World Health

434 Organization (Andersen, 1978). Data from a follow up experiment with 6 one-hour work bouts

435 on a single day, show that this heart rate represents a full day limit with participants feeling very

436 fatigued upon cessation (Smallcombe et al., 2019). However, it is possible that e.g., for shorter

437 periods than a day, a higher limit for the fixed heart rate is possible, and that with higher heart

438 rates (i.e., higher workloads), core temperature and dehydration may become a more relevant

439 predictor of the loss in PWC.

440 WBGT and UTCI are commonly used heat stress indices in biometeorology, and their values

441 account for any change in mean radiant temperature (Havenith and Fiala, 2015). We show that,

442 based on the change in mean radiant temperature with SOLAR (determined empirically by black

443 globe temperature combined with $T_{\mathrm{a}}$ and $\mathrm{Rh}$ ), the relative shift in the value of WBGT and UTCI

444 predicts the reduction in PWC caused by SOLAR appropriately. Therefore, assuming that globe

445 temperature is correctly measured (spatially and allowed to equilibrate), the WBGT and UTCI

446 can accurately predict PWC in both shaded and unshaded conditions with a single equation. The 
447 validity of models that use WBGT to predict PWC (Dunne et al., 2013; Kjellstrom et al., 2018) is

448 therefore not reduced if also applied to outdoor work settings. In contrast, the $T_{\mathrm{wb}}$, Humidex, and

449 Heat Index do not intrinsically account for any change in mean radiant temperature, highlighting

450 the importance of context if such indices are linked with human physiology or survival.

451 Correction factors for PWC are provided if such indices are to be used for outdoor work with

452 SOLAR, as shown in Table 2. The equations reported in this study have immediate applicability

453 for those studying the impact of hot weather on PWC, especially in outdoor settings.

\section{Limitations}

455 There are several limitations of the present study that should be considered. Firstly, it is unclear

456 if the general conclusions about SOLAR are accurate during exposure to a full working day, in

457 contrast to the 1-hour work bout used in our study. Preliminary data from our lab (Smallcombe et

458 al., 2019) indicates minimal impact of work duration on PWC until WBGT reaches $36^{\circ} \mathrm{C}$, which

459 is only surpassed at $45^{\circ} \mathrm{C} / 20 \% \mathrm{Rh}$ and $35^{\circ} \mathrm{C} / 80 \% \mathrm{Rh}$ with the addition of SOLAR. Finally, a

460 constant intensity of $800 \mathrm{~W} \cdot \mathrm{m}^{-2} \mathrm{SOLAR}$ was chosen for this study. Ideally, different intensities

461 would be measured to improve impact analysis in different regions or times of day. The choice

462 of radiation intensity and radiated surface area represented a worst-case scenario, simulating

463 outdoor work under direct sunlight at the hottest part of the day (Monteith and Unsworth, 1990).

464 The correction factors are thus based on the assumption that the radiation level can be described

465 as a linear impact between our shade and $800 \mathrm{~W} \cdot \mathrm{m}^{-2}$ condition. While from a heat balance

466 modelling perspective, this is deemed plausible, research should verify the validity of this

467 assumption.

\section{Conclusions}


469 Addition of solar radiation to climatic heat stress reduced PWC by up to a further $20 \%$, above the

470 SHADE condition depending on the temperature, humidity, and clothing condition. We observed

471 an interactive effect of solar radiation on physical work capacity, depending on clothing

472 coverage and the climate. WBGT and UTCI account well for the impact of solar radiation on

473 physical work capacity. Correction factors are available if using $T_{\mathrm{wb}}$, humidex, or heat index for

474 the prediction of physical work capacity, in solar radiation conditions.

\section{$475 \quad$ Funding}

476 Funding was provided by 'HEAT-SHIELD', European Union's Horizon 2020 research and

477 innovation programme under grant agreement no. 668786. 


\section{References}

Aburto-Corona, J., and Aragón-Vargas, L. (2016). Sunscreen use and sweat production in men and women. J. Athl. Train. 51, 696-700. doi:10.4085/1062-6050-51.11.01.

Adolph, E. (1947). Physiology of Man in the Desert. Hafner Publishing.

Andersen, K. L. (1978). Habitual physical activity and health. 188.

Armstrong, L. E., Maresh, C. M., Castellani, J. W., Bergeron, M. F., Kenefick, R. W., LaGasse, K. E., et al. (1994). Urinary indices of hydration status. Int. J. Sport Nutr. 4, 265-79. doi:10.1123/ijsn.4.3.265.

Bates, G. P., and Schneider, J. (2008). Hydration status and physiological workload of UAE construction workers: A prospective longitudinal observational study. J. Occup. Med. Toxicol. 3, 21. doi:10.1186/1745-6673-3-21.

Beeson, E. J. G. (1978). The CSI lamp as a source of radiation for solar simulation. Light. Res. Technol. doi:10.1177/096032717801000307.

Bernard, T. E., and Pourmoghani, M. (1999). Prediction of workplace wet bulb global temperature. Appl. Occup. Environ. Hyg. 14, 126-134. doi:10.1080/104732299303296.

Bröde, P., Fiala, D., Błażejczyk, K., Holmér, I., Jendritzky, G., Kampmann, B., et al. (2012). Deriving the operational procedure for the Universal Thermal Climate Index (UTCI). Int. J. Biometeorol. 56, 481-494. doi:10.1007/s00484-011-0454-1.

Bröde, P., Kuklane, K., Candas, V., den Hartog, E., Griefahn, B., Holmer, I., et al. (2008). Heat transfer through protective clothing under symmetric and asymmetric long wave thermal radiation. Zeitschrift fuer Arbeitswiss. 62, 267-276.

Bröde, P., Kuklane, K., Candas, V., Kuklane, K., Griefahn, B., Holmér, I., et al. (2010a). Heat gain from thermal radiation through protective clothing with different insulation, reflectivity and vapour permeability. Int. J. Occup. Saf. Ergon. 16, 231-244. doi:10.1080/10803548.2010.11076842.

Bröde, P., Kuklane, K., Candas, V., Kuklane, K., Griefahn, B., Holmér, I., et al. (2010b). Heat gain from thermal radiation through protective clothing with different insulation, reflectivity and vapour permeability. Int. J. Occup. Saf. Ergon. doi:10.1080/10803548.2010.11076842.

Clark, J. A., and Cena, K. (1978). Net radiation and heat transfer through clothing: The effects of insulation and colour. Ergonomics 21, 691-696. doi:10.1080/00140137808931771.

Cohen, J. (1988). Statistical Power Analysis for the Behavioural Science (2nd Edition).

Connolly, A. J. D., and Wilcox, A. R. (2000). The effects of an application of suncream on selected physiological variables during exercise in the heat. J. Sports Med. Phys. Fitness 40, $35-40$.

513 Dunne, J., Stouffer, R., and John, J. (2013). Reductions in labour capacity from heat stress under

514 climate warming. Nat. Clim. Chang. 3, 563-566. doi:10.1038/nclimate1827. 
Flouris, A. D., Dinas, P. C., Ioannou, L. G., Nybo, L., Havenith, G., Kenny, G. P., et al. (2018). Workers' health and productivity under occupational heat strain: a systematic review and meta-analysis. Lancet. Planet. Heal. 2, e521-e531. doi:10.1016/S2542-5196(18)30237-7.

Foster, J., Smallcombe, J., Hodder, S., Jay, O., Flouris, A., and Havenith, G. (2021a). [submitted paper] The impact of heat and climate change on human physical work capacity; 2: the role of wind (fans) in mitigating heat strain. Int. J. Biometeorol.

Foster, J., Smallcombe, J., Hodder, S., Jay, O., Flouris, A., Nybo, L., et al. (2021b). An advanced empirical model for quantifying the impact of heat and climate change on human physical work capacity. Int. J. Biometeorol. In Press.

Fox, R. H., Goldsmith, R., Kidd, D. J., and Lewis, H. E. (1963). Blood flow and other thermoregulatory changes with acclimatization to heat. J. Physiol. 166, 548-62.

Gagge, A. P., and Hardy, J. D. (1967). Thermal radiation exchange of the human by partitional calorimetry. J. Appl. Physiol. 23, 248-258. doi:10.1152/jappl.1967.23.2.248.

Gonzalez, R. R., Cheuvront, S. N., Ely, B. R., Moran, D. S., Hadid, A., Endrusick, T. L., et al. (2012). Sweat rate prediction equations for outdoor exercise with transient solar radiation. $J$. Appl. Physiol. 112, 1300-1310. doi:10.1152/japplphysiol.01056.2011.

Hardy, J. D., and Stoll, A. M. (1954). Measurement of radiant heat load on man in summer and winter Alaskan climates. J. Appl. Physiol. 7, 200-211. doi:10.1152/jappl.1954.7.2.200.

Havenith, G., and Fiala, D. (2015). Thermal Indices and Thermophysiological Modeling for Heat Stress. Compr. Physiol. 6, 255-302. doi:10.1002/cphy.c140051.

Hodder, S. G., and Parsons, K. (2007). The effects of solar radiation on thermal comfort. Int. J. Biometeorol. doi:10.1007/s00484-006-0050-y.

Hsiang, S., Kopp, R., Jina, A., Rising, J., Delgado, M., Mohan, S., et al. (2017). Estimating economic damage from climate change in the United States. Science (80-. ). 356, 1362 1369. doi:10.1126/science.aal4369.

Hübler, M., Klepper, G., and Peterson, S. (2008). Costs of climate change: The effects of rising temperatures on health and productivity in Germany. Ecol. Econ. 68, 381-393. doi:10.1016/j.ecolecon.2008.04.010.

Ioannou, L. G., Mantzios, K., Tsoutsoubi, L., Panagiotaki, Z., Kapnia, A. K., Ciuha, U., et al. (2021). Effect of a Simulated Heat Wave on Physiological Strain and Labour Productivity. Int. J. Environ. Res. Public Health 18, 3011. doi:10.3390/ijerph18063011.

Ioannou, L. G., Tsoutsoubi, L., Samoutis, G., Bogataj, L. K., Kenny, G. P., Nybo, L., et al. (2017). Time-motion analysis as a novel approach for evaluating the impact of environmental heat exposure on labor loss in agriculture workers. Temperature. doi:10.1080/23328940.2017.1338210.

ISO9920 (2009). International Standardisation Organisation. Ergonomics of the thermal environment - Estimation of thermal insulation and water vapour resistance of a clothing ensemble. 
Jay, O., Hoelzl, R., Weets, J., Morris, N., English, T., Nybo, L., et al. (2019). Fanning as an alternative to air conditioning - A sustainable solution for reducing indoor occupational heat stress. Energy Build. 193, 92-98. doi:10.1016/j.enbuild.2019.03.037.

Kalkowsky, B., and Kampmann, B. (2006). Physiological strain of miners at hot working places in German coal mines. Ind. Health 44, 465-73.

Kjellstrom, T., Freyberg, C., Lemke, B., Otto, M., and Briggs, D. (2018). Estimating population heat exposure and impacts on working people in conjunction with climate change. Int J Biometeorol 62, 291-306. doi:10.1007/s00484-017-1407-0.

Lloyd, A., and Havenith, G. (2016). Interactions in human performance: An individual and combined stressors approach. Temperature 3, 514-517. doi:10.1080/23328940.2016.1189991.

Ludlow, L. W., and Weyand, P. G. (2017). Walking economy is predictably determined by speed, grade, and gravitational load. J. Appl. Physiol. 123, 1288-1302. doi:10.1152/japplphysiol.00504.2017.

Mairiaux, P., and Malchaire, J. (1985). Workers self-pacing in hot conditions: A case study. Appl. Ergon. 16, 85-90. doi:10.1016/0003-6870(85)90209-1.

Masterton, J., and Richardson, F. (1979). Humidex: a method of quantifying human discomfort due to excessive heat and humidity. Environment Canada, Atmospheric Environment.

Miller, G. (2012). "Chapter 14 - Biomedical Transport Processes," in Introduction to Biomedical Engineering (Third Edition) Biomedical Engineering., eds. J. D. Enderle and J. D. Bronzino (Boston: Academic Press), 937-993. doi:http://dx.doi.org/10.1016/B978-0-12-3749796.00015-0.

Miller, V., Bates, G., Schneider, J. D., and Thomsen, J. (2011). Self-Pacing as a Protective Mechanism against the Effects of Heat Stress. Ann. Occup. Hyg. 55, 548-555. doi:10.1093/annhyg/mer012.

Monteith, J. L., and Unsworth, M. H. (1990). Principles of environmental physics, 2nd Edition. Edward Arnold, London. doi:10.1016/B978-0-12-386910-4.00026-3.

Nielsen, B. (1990). Solar heat load: heat balance during exercise in clothed subjects. Eur. J. Appl. Physiol. Occup. Physiol. 60, 452-6. doi:10.1007/bf00705036.

Nielsen, B., Kassow, K., and Aschengreen, F. E. (1988). Heat balance during exercise in the sun. Eur. J. Appl. Physiol. Occup. Physiol. 58, 189-96. doi:10.1007/bf00636625.

Otani, H., Goto, T., Goto, H., and Shirato, M. (2017). Time-of-day effects of exposure to solar radiation on thermoregulation during outdoor exercise in the heat. Chronobiol. Int. 34, 1224-1238. doi:10.1080/07420528.2017.1358735.

Otani, H., Kaya, M., Tamaki, A., Goto, H., and Maughan, R. J. (2019). Exposure to high solar radiation reduces self-regulated exercise intensity in the heat outdoors. Physiol. Behav. 199, 191-199. doi:10.1016/j.physbeh.2018.11.029.

Otani, H., Kaya, M., Tamaki, A., Watson, P., and Maughan, R. J. (2016). Effects of solar 
602

603

604

605

606

607

608

609

radiation on endurance exercise capacity in a hot environment. Eur. J. Appl. Physiol. 116, 769-779. doi:10.1007/s00421-016-3335-9.

Parsons, K. C. (2010). Human thermal environments. 2nd ed. London: Taylor \& Francis doi:10.4324/9780203302620_chapter_1.

Piil, J. F., Christiansen, L., Morris, N. B., Mikkelsen, C. J., Ioannou, L. G., Flouris, A. D., et al. (2020). Direct exposure of the head to solar heat radiation impairs motor-cognitive performance. Sci. Rep. 10, 1-10. doi:10.1038/s41598-020-64768-w.

Ramanathan, N. L. (1964). A new weighting system for mean surface temperature of the human body. J. Appl. Physiol. 19, 531-533. doi:10.1152/jappl.1964.19.3.531.

Ran, C., Hoon, M. A., and Chen, X. (2016). The coding of cutaneous temperature in the spinal cord. Nat. Neurosci. 19, 1201-1209. doi:10.1038/nn.4350.

Rana, R., Kusy, B., Jurdak, R., Wall, J., and Hu, W. (2013). Feasibility analysis of using humidex as an indoor thermal comfort predictor. Energy Build. 64, 17-25. doi:10.1016/j.enbuild.2013.04.019.

Ravanelli, N., and Jay, O. (2020). The Change in Core Temperature and Sweating Response during Exercise Are Unaffected by Time of Day within the Wake Period. Med. Sci. Sport. Exerc. doi:10.1249/mss.0000000000002575.

Rothfusz, L. P. (1990). The Heat Index "Equation" (or, More Than You Ever Wanted to Know About Heat Index).

Smallcombe, J., Foster, J., Hodder, S., Jay, O., Flouris, A. D., and Havenith, G. (2019). Quantifying physical work capacity in the heat: one hour vs full day exposure. in International Conference on Environmental Ergonomics, 128.

Stolwijk, J. A., and Hardy, J. D. (1965). Skin and subcutaneous temperature changes during exposure to intense thermal radiation. J. Appl. Physiol. 20, 1006-1013. doi:10.1152/jappl.1965.20.5.1006.

Turner, B. D., Henley, B. J., Sleap, S. B., and Sloan, S. W. (2015). Kinetic model selection and the Hill model in geochemistry. Int. J. Environ. Sci. Technol. doi:10.1007/s13762-0140662-4.

Underwood, C. R., and Ward, E. J. (1966). The solar radiation area of man. Ergonomics. doi:10.1080/00140136608964361.

Vogt, J. J., Libert, J. P., Candas, V., Daull, F., and Mairjaux, P. (1983). Heart rate and spontaneous work-rest cycles during exposure to heat. Ergonomics 26, 1173-1185. doi:10.1080/00140138308963453.

Waterhouse, J., Edwards, B., Bedford, P., Hughes, A., Robinson, K., Nevill, A., et al. (2004). Thermoregulation During Mild Exercise at Different Circadian Times. Chronobiol. Int. 21, 253-275. doi:10.1081/CBI-120037799.

Wyndham, C. H. (1973). The effects of heat stress upon human productivity. Arch. Sci. Physiol. (Paris). 27, 491-7. 
bioRxiv preprint doi: https://doi.org/10.1101/2021.07.01.449782; this version posted July 2, 2021. The copyright holder for this preprint (which was not certified by peer review) is the author/funder. All rights reserved. No reuse allowed without permission.

629 Zander, K., Botzen, W., and Oppermann, E. (2015). Heat stress causes substantial labour 630 productivity loss in Australia. Nat. Clim. 5, 647-651.

631

632 
633 Table 1. Participant characteristics. Data are presented as means \pm standard deviation. The data

634 range are presented in parentheses.

\begin{tabular}{|c|c|c|c|c|}
\hline \multirow{2}{*}{$\begin{array}{l}\text { Variable } \\
\text { Age (years) }\end{array}$} & \multicolumn{2}{|c|}{$\begin{array}{l}\text { Low Clothing Coverage } \\
\qquad(\mathbf{n}=7)\end{array}$} & \multicolumn{2}{|c|}{$\begin{array}{c}\text { High Clothing } \\
\text { Coverage }(\mathbf{n}=7)\end{array}$} \\
\hline & $25 \pm 3$ & $(20-29)$ & $23 \pm 3$ & $(20-28)$ \\
\hline Height (cm) & $177 \pm 5$ & $(171-185)$ & $178 \pm 6$ & $(172-192)$ \\
\hline Mass (kg) & $74 \pm 10$ & $(59-92)$ & $74 \pm 11$ & $(59-94)$ \\
\hline Body Surface Area $\left(\mathrm{m}^{-2}\right)$ & $1.9 \pm 0.1$ & $(1.7-2.2)$ & $1.9 \pm 0.1$ & $(1.7-2.1)$ \\
\hline Body Mass Index $\left(\mathrm{kg} \cdot \mathrm{m}^{-2}\right)$ & $23 \pm 2$ & $(20-28)$ & $23 \pm 3$ & $(20-29)$ \\
\hline Body fat (\%) & $18 \pm 6$ & $(10-27)$ & $14 \pm 4$ & $(9-21)$ \\
\hline$V \square \mathbf{O}_{2 \max }\left(\mathbf{L} \cdot \min ^{-1}\right)$ & $3.8 \pm 0.8$ & $(2.6-5.9)$ & $4.2 \pm 0.0$ & $(2.7-5.3)$ \\
\hline$V \square O_{2 \max }\left(\mathbf{m L} \cdot \mathrm{kg}^{-1} \cdot \mathrm{min}^{-1}\right)$ & $52 \pm 9$ & $(40-65)$ & $56 \pm 5$ & $(44-64)$ \\
\hline
\end{tabular}

$V \square \mathrm{O}_{2 \text { max }}$, maximal oxygen consumption; BMI, body mass index; BSA, body surface area; $\mathrm{L}$, litres; mL, millilitres; 
637 Table 2. Correction factors for calculation of physical work capacity in outdoor working 638 conditions with exposure to SOLAR. The values need to be subtracted from the shaded values in 639 our companion paper as in Eq 10 (Foster et al., 2021b).

\section{Correction factor}

Low Clothing Coverage ( 0.26 clo)

WBGT

\section{Not required}

UTCI

\section{Not Required}

$T_{\mathrm{wb}}$

$$
\boldsymbol{P} \boldsymbol{W} \boldsymbol{C}_{\text {corr }}=21.04 \times e^{\left[-0.5\left(\frac{T_{w b}-30.51}{8.505}\right)^{2}\right]}
$$

Humidex

$$
\boldsymbol{P W} \boldsymbol{C}_{\text {corr }}=21.02 \times e^{\left[-0.5\left(\frac{\text { Humidex }-50.65}{10.54}\right)^{2}\right]}
$$

Heat Index

$$
\boldsymbol{P W} \boldsymbol{C}_{\text {corr }}=21.10 \times e^{\left[-0.5\left(\frac{\text { Heat Index-49.35 }}{13.02}\right)^{2}\right]}
$$

$\underline{\text { High Clothing Coverage (0.86 clo) }}$

WBGT

$$
\text { Not required }
$$

$12-40^{\circ} \mathrm{C}$

UTCI

\section{Not Required}

$T_{\mathrm{wb}}$

$$
\boldsymbol{P} \boldsymbol{W} \boldsymbol{C}_{\text {corr }}=11.18 \times e^{\left[-0.5\left(\frac{T_{w b}-21.67}{9.234}\right)^{2}\right]}
$$

Humidex

$$
\boldsymbol{P} \boldsymbol{W} \boldsymbol{C}_{\text {corr }}=10.73 \times e^{\left[-0.5\left(\frac{\text { Humidex }-43.95}{15.99}\right)^{2}\right]}
$$

Heat Index

$$
\boldsymbol{P} \boldsymbol{W} \boldsymbol{C}_{\text {corr }}=11.34 \times e^{\left[-0.5\left(\frac{\text { Heat Index }-44.02}{18.05}\right)^{2}\right]}
$$

\section{Range}

$12-40^{\circ} \mathrm{C}$

$15-63^{\circ} \mathrm{C}$

$10-39^{\circ} \mathrm{C}$

$13-71^{\circ} \mathrm{C}$

Eq 11

$14-85^{\circ} \mathrm{C}$

Eq 12 

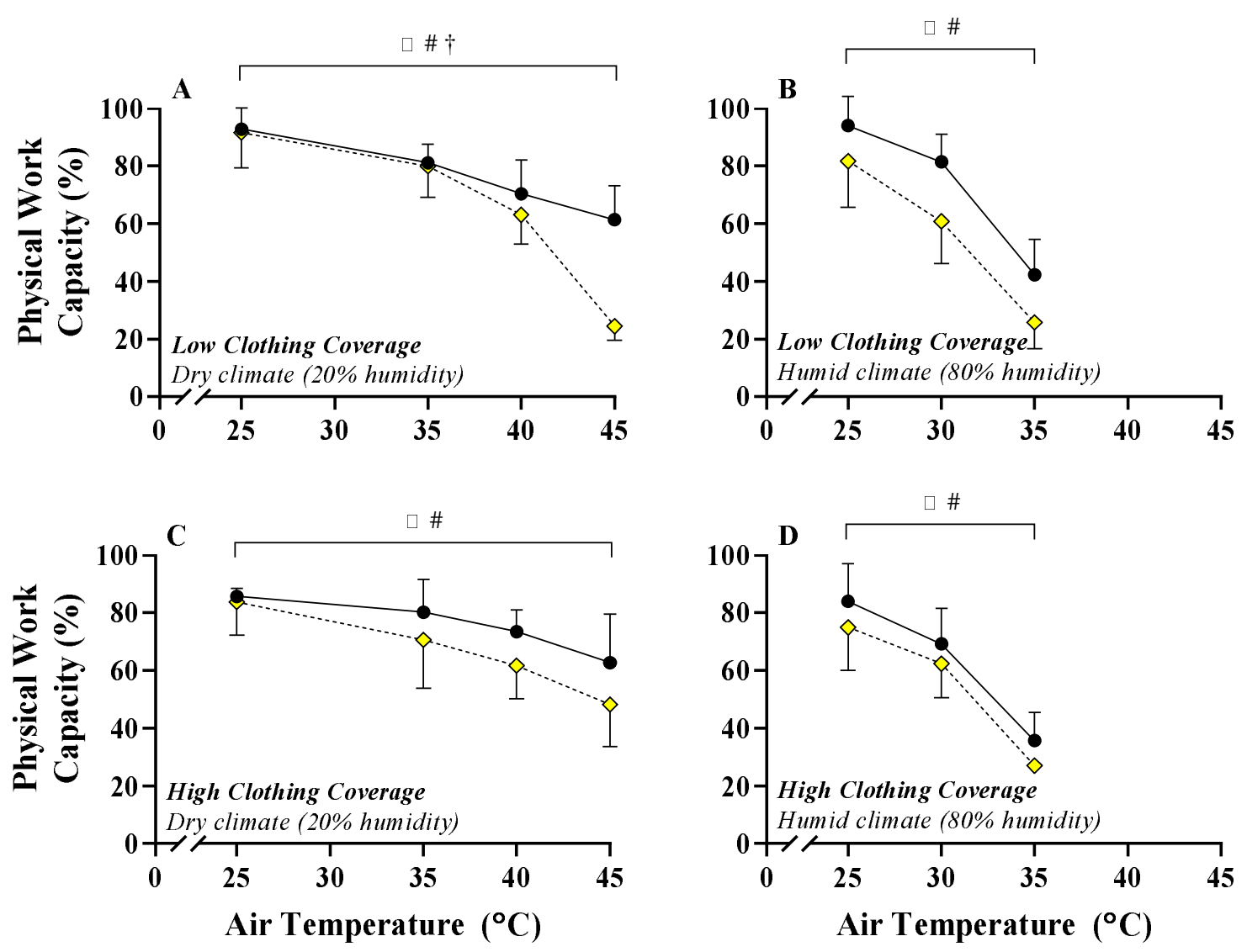

642

643 Figure 1. Change in absolute physical work capacity in SHADE (black circles) with SOLAR (yellow diamonds) in low (A and B) or high (C and D) clothing coverage conditions, in dry (A and C) and humid (B and D) climates. 固 \#

645

646 denote main effects for condition and air temperature. $\uparrow$ denotes an interaction effect between condition and air temperature. 

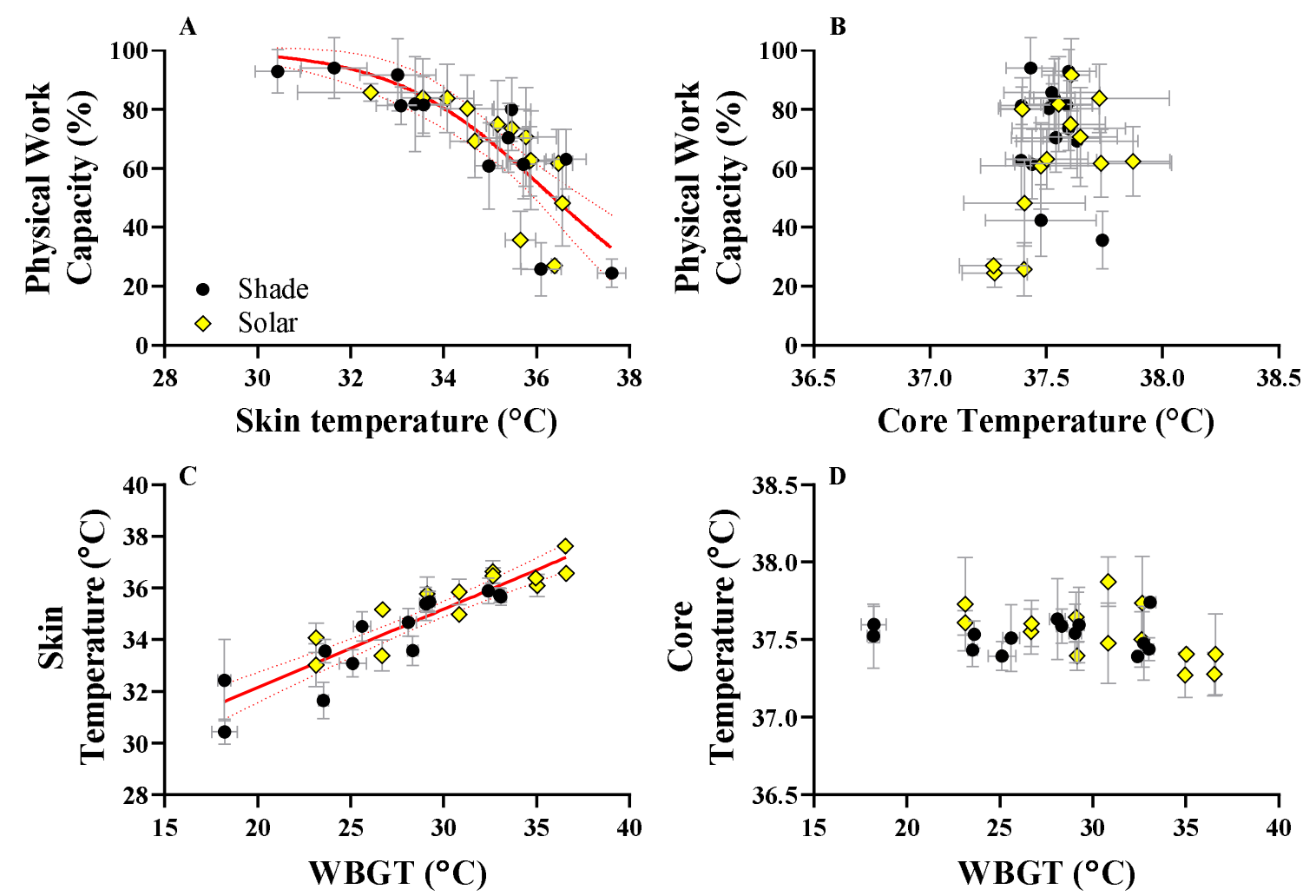

648

649 Figure 2. Increased skin, but not core temperature, is associated with PWC in the heat. Graphs A and B show the

650 skin and core temperature (average over each trial) relationship with PWC, respectively. Graphs C and D show the

651 skin and core temperature responses to varying WBGT while working at a fixed heart rate. Predictive power $\left(\mathrm{R}^{2}\right)$ for

652 models A and C were 0.68 and 0.82, respectively. Data is pooled for both clothing conditions. Black circles are

653 SHADE trials, yellow diamonds are SOLAR trials. Dotted lines represent 95\% confidence bands. 

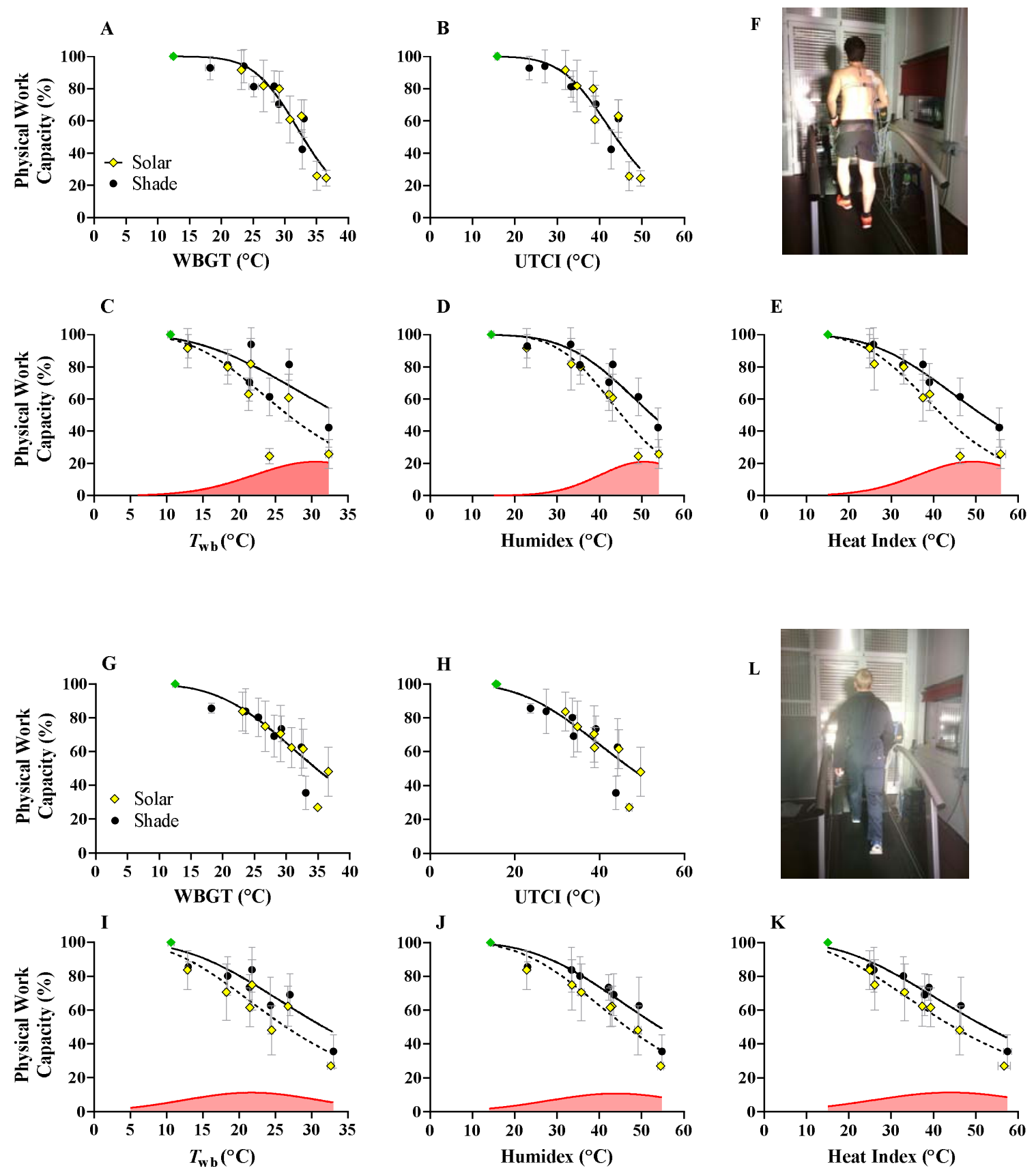

656 Figure 3. Physical work capacity (PWC) with low (A-F) and high clothing coverage (G-L). Black circles and

657 yellow diamonds represent SHADE and SOLAR trials, respectively. For WBGT and UTCI, a pooled model is

658 sufficient for predicting PWC even if solar data are included. For psychrometric wet-bulb $\left(T_{\mathrm{wb}}\right)$, Humidex, and Heat

659 Index, separate models are required if predicting PWC during SOLAR exposure. This was true for low and high

660 clothing coverage. Here, the solid line and dotted line in figures represent SHADE and SOLAR data models, 
661 respectively. The difference in PWC (i.e. shade - solar) for models followed a guassian distribution, and is shown by

662 the red area fill. These guassian models are shown in Table 4 and were required for the generation of correction

663 factors, allowing computation of outdoor PWC for $T_{\mathrm{wb}}$, Humidex, and Heat Index. The clothing ensembles are

664 shown in panels $\mathrm{F}$ and $\mathrm{L}$. 